$02 ; 13$

\title{
Влияние температуры мишени на образование нанорельефа при облучении газовыми кластерными ионами
}

\author{
() Д.С. Киреев ${ }^{1}$, А.Е. Иешкин ${ }^{1}$, А.А. Шемухин ${ }^{2}$ \\ ${ }^{1}$ Московский государственный университет им. М.В. Ломоносова, Москва, Россия \\ ${ }^{2}$ Научно-исследовательский институт ядерной фризики им. Д.В. Скобельцына Московского государственного \\ университета им. М.В. Ломоносова, Москва, Россия \\ E-mail: dmtr.kireeff6497@yandex.ru
}

Поступило в Редакцию 28 августа 2019г.

В окончательной редакции 31 января 2020г.

Принято к публикации 6 фревраля 2020г.

Проведено исследование нанорельефа, формирующегося на поверхности меди под действием наклонного пучка кластерных ионов при различных дозах обучения и температурах мишени. Образующийся нанорельеф с увеличением дозы развивается в упорядоченную волнообразную структуру. Обнаружено, что при увеличении температуры мишени происходит сглаживание исходной шероховатости. Указаны механизмы, ответственные за формирование топографии поверхности, и сделаны оценки их эффективности.

Ключевые слова: кластерные ионы, распыление, нанорельеф, самоорганизация, атомно-силовая микроскопия.

DOI: 10.21883/PJTF.2020.09.49362.18021

Современные технологии, применяемые при производстве элементов и устройств электроники, оптики, сенсорики, предъявляют высокие требования к состоянию поверхности материалов, в частности к имеющемуся на поверхности рельефу. Эти требования варьируются в зависимости от типа прикладных задач. Например, быстрый рост степени интеграции в электронных схемах значительно влияет на требования к планарности поверхности полупроводниковых структур на всех этапах создания микросхем и высокому качеству кристалличности интерфейсных слоев [1]. Одним из способов достижения высокого уровня гладкости поверхности различных материалов является использование ионных пучков. В частности, хорошо зарекомендовала себя в этой области технология ускоренных газовых кластерных ионов [2-4].

Известно, что сглаживание шероховатостей кластерными ионами происходит при нормальном падении ионного пучка на поверхность. Напротив, наклонное падение пучка может приводить к развитию поверхностного нанорельефа [5]. Появление волнообразного рельефа на кремнии было продемонстрировано в [6], аналогичный рельеф на золоте исследован в [7]. Обзор имеющихся на настоящий момент данных, касающихся формирования волн при наклонном падении кластерных ионов, приведен в [8]; там обсуждаются возможности использования этого явления, например, для создания сенсорных структур на основе плазмонного резонанса.

Несмотря на то что существует большое количество работ, направленных на исследование возможности сглаживания и модификации поверхности с помощью пучков ускоренных кластерных ионов, на данный момент процессы формирования рельефа на облучаемой поверхности не изучены в достаточной степени. В частности, неизвестна роль температуры облучаемой мишени. В настоящей работе описан нанорельеф, формирующийся на поверхности меди при облучении кластерными ионами аргона в случае наклонного падения при комнатной температуре и нагреве мишени.

Облучение проводилось на ускорителе газовых кластерных ионов МГУ им. М.В. Ломоносова. Более подробно параметры данной установки и основные механизмы формирования кластерных ионов описаны в [9]. В качестве рабочего газа, из которого формировались кластерные ионы, использовался аргон особой чистоты. Поток кластерных ионов генерировался при адиабатическом расширении рабочего газа через сверхзвуковое сопло и последующей ионизации образовавшихся нейтральных кластеров. Полученные ионы ускорялись напряжением $10 \mathrm{kV}$. Процессы, происходящие при столкновении с мишенью атомарных и легких кластер-

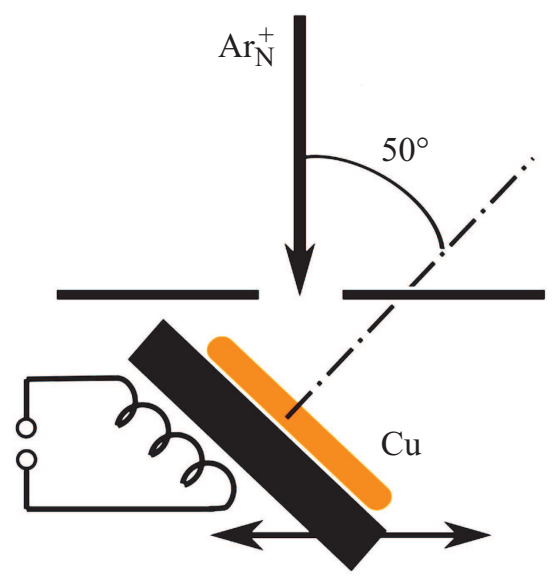

Рис. 1. Схема эксперимента. 
$a$

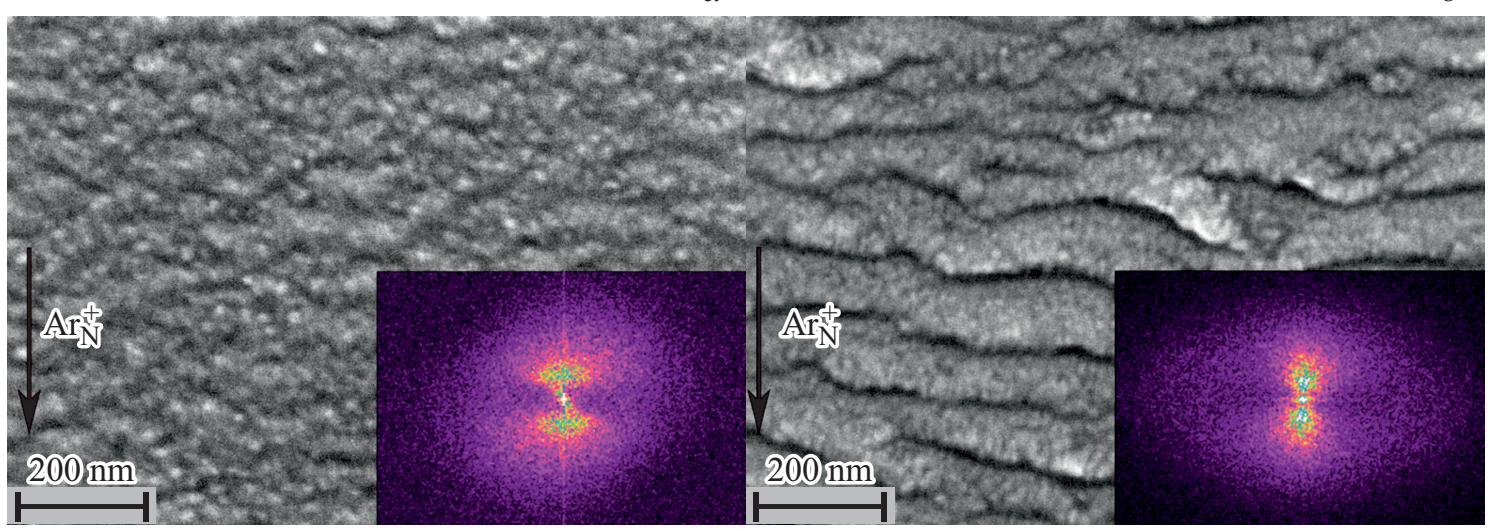

Рис. 2. РЭМ-изображения поверхности меди при облучении дозами $1.2 \cdot 10^{16}\left(\right.$ a) и $4.2 \cdot 10^{16}$ ion $/ \mathrm{cm}^{2}(b)$ при комнатной температуре. На вставках приведены двумерные фурье-образы изображений, полученные методом БПФ. Стрелкой показано направление падения пучка кластерных ионов.

ных ионов, имеющих сравнительно высокую энергию на составляющий атом, коренным образом отличаются от случая тяжелых кластерных ионов [10]. Поэтому ускоренный ионный пучок проходил через область постоянного магнитного поля, и на мишень попадали кластерные ионы, состоящие более чем из 70 атомов аргона. Средний размер кластерных ионов, попадающих на мишень, контролировался времяпролетной системой и составлял 1200 атомов аргона на элементарный заряд.

Образцы были вырезаны из чистой поликристаллической меди в виде прямоугольных пластин размером $20 \times 10 \times 1.5 \mathrm{~mm}$. Поверхность полировалась свободным абразивом и очищалась в органических растворителях в ультразвуковой ванне. Среднеквадратичная остаточная шероховатость составляла $3-5 \mathrm{~nm}$. При облучении кластерными ионами образец закреплялся на поверхности нагревателя, нормаль к поверхности которого составляла угол $50^{\circ}$ к линии падения ионного пучка. Выбор угла обусловлен тем, что, согласно [7], наиболее эффективно рельеф развивается при углах падения кластеров в диапазоне 40-65․ Перед мишенью располагалась диафрагма диаметром $3 \mathrm{~mm}$, изготовленная из титановой фольги (рис. 1). При проведении эксперимента каждый из образцов нагревался до температуры $400^{\circ} \mathrm{C}$, затем при этой температуре осуществлялось его облучение с выбранной дозой, после чего образец остужался до комнатной температуры, смещался относительно диафрагмы и облучался с той же дозой при комнатной температуре. Температура мишени контролировалась термопарой. Облучение проводилось в вакууме, уровень которого составлял $2 \cdot 10^{-3}$ Ра при нагреве мишени и $4 \cdot 10^{-4} \mathrm{~Pa}$ в отсутствие нагрева. Дозы облучения измерялись интегратором тока и в приближении однозарядных ионов равнялись $1.2 \cdot 10^{16}$ и $4.2 \cdot 10^{16} \mathrm{~cm}^{-2}$.

Рельеф поверхности перед облучением и после него контролировался с помощью растрового электронного микроскопа (РЭМ) ZEISS Ultra 55 и атомно-силового микроскопа (ACM) NT-MDT Solver Pro в полуконтактном режиме.

РЭМ-изображения области, облученной при комнатной температуре, приведены на рис. 2. На вставках представлены двумерные фурье-образы аналогичных изображений при меньшем увеличении, полученные методом быстрого преобразования Фурье (БПФ). При дозе облучения $1.2 \cdot 10^{16} \mathrm{~cm}^{-2}$ на поверхности наблюдается слабо развитый рельеф, образованный зернами с характерным размером 15-20 nm. БПФ демонстрирует некоторую степень его упорядоченности в плоскости падения пучка. С увеличением дозы облучения развивается хорошо выраженный волнообразный рельеф с волновым вектором, лежащим в плоскости падения пучка. Длина волны составляет $145 \mathrm{~nm}$ и соответствует максимуму фурьепреобразования. Заметно, что, как и в случае меньшей дозы облучения, рельеф имеет зернистую структуру. Области образцов, облученные при температуре $400^{\circ} \mathrm{C}$, на РЭМ-изображениях выглядят гладкими вне зависимости от дозы, и эти изображения мы не приводим.

На рис. 3 представлены результаты исследования с помощью АСМ поверхности образца, облученного дозой $4.2 \cdot 10^{16} \mathrm{~cm}^{-2}$. Среднеквадратичные значения шероховатости, определенные по области размером $2 \times 2 \mu \mathrm{m}$, составляют $7.3 \mathrm{~nm}$ для комнатной температуры облучения и $0.7 \mathrm{~nm}$ для повышенной температуры. Последнее значение существенно ниже исходной величины шероховатости. Таким образом, ионная бомбардировка в таких условиях не только не приводит к развитию волнообразного рельефа, но и обеспечивает сглаживание поверхности.

Определенная по профилю АСМ-изображения характерная высота волнообразного рельефа от впадины до выступа равняется $15-20 \mathrm{~nm}$, длина волны соответствует приведенному ранее значению $145 \mathrm{~nm}$. Отметим, что длина волны наблюдаемого нами рельефа точно укладывается в закономерность, полученную в [6] для золота, облученного кластерами со средним размером 

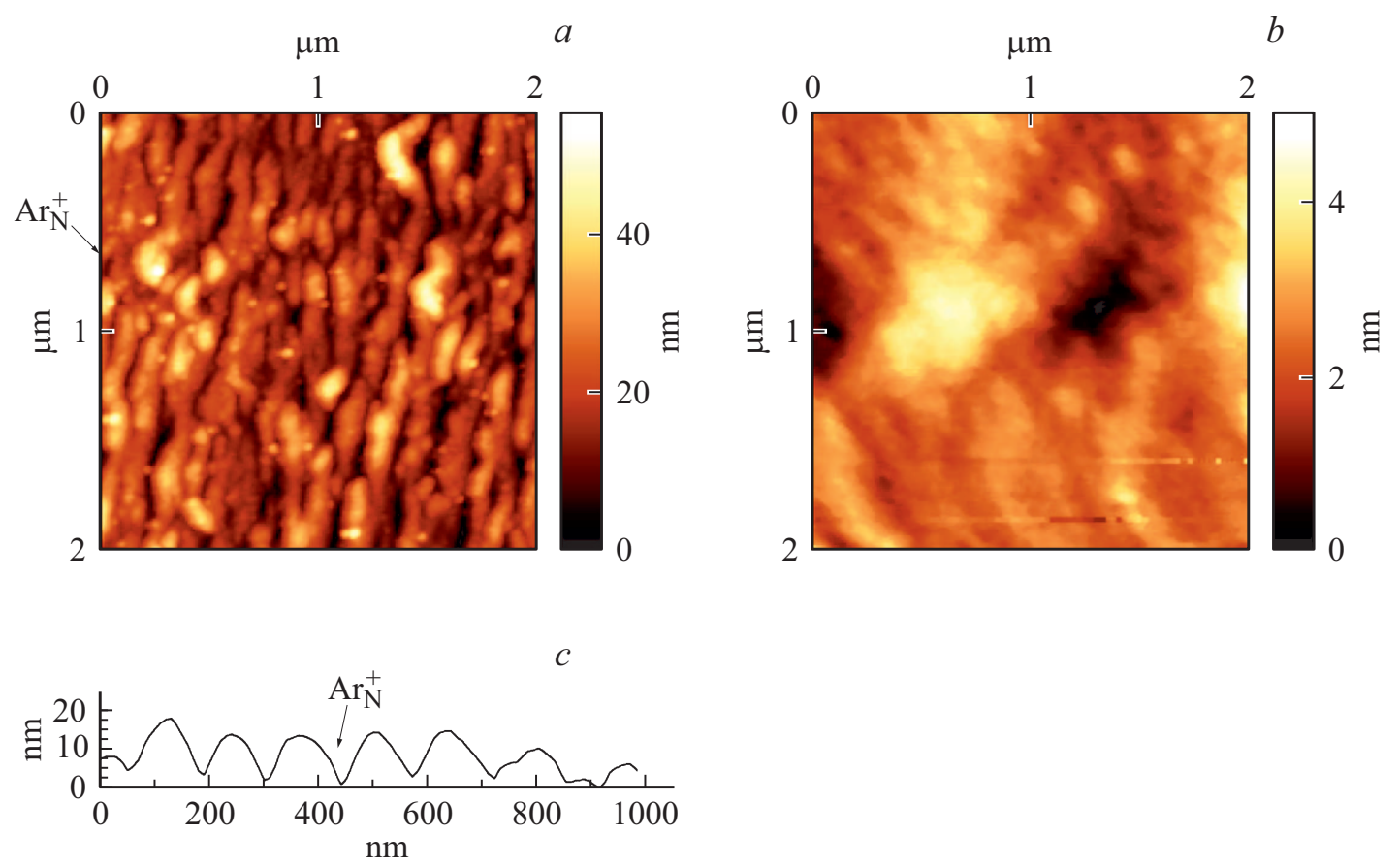

Рис. 3. АСМ-изображения поверхности меди при облучении дозой $4.2 \cdot 10^{16} \mathrm{ion} / \mathrm{cm}^{2}: a-$ при комнатной температуре, $b-$ при температуре $400^{\circ}$ C. $c$ - профиль волнообразного рельефа, образованного при комнатной температуре. Стрелками показано направление падения пучка кластерных ионов.

3000 атомов аргона и энергией $30 \mathrm{keV}$, т.е. со средней энергией в расчете на один атом кластера, близкой к нашей; среднеквадратичная шероховатость также близка к значению, указанному в этой работе.

Оценка эффективной толщины удаленного кластерами слоя вещества [11] с учетом зависимости коэффициента распыления от угла падения [12] дает значения 30-50 nm. Это незначительно превосходит глубину волнообразного рельефа. Таким образом, только зависимость коэффициента распыления от локальных угла падения и кривизны поверхности не может привести к формированию такого рельефа. Его формирование обеспечивается также за счет перераспределения вещества вдоль поверхности при диффузии и переосаждении распыленных атомов [13].

В то же время поверхностная диффузия обеспечивает механизм сглаживания рельефа. Оценим изменение коэффициента поверхностной диффузии $D_{s}$ при нагреве мишени. Считая, что коэффициент $D_{s}$ равен произведению концентрации адатомов $n_{a}$ на коэффициент их диффузии $D_{a}[14]$, получаем

$$
D_{s}=n_{a} D_{a}=n_{a} D_{0} \exp \left(-\frac{E_{m}^{a}}{k T}\right),
$$

где $E_{m}^{a}$ - энергия миграции адатома. В условиях ионного облучения в приведенной выше формуле предэкспоненциальный множитель определяется в основном темпом генерации дефектов на поверхности и остается неизменным в условиях эксперимента. Подстановка значений энергии миграции [14] показывает, что изменение температуры от комнатной до $400^{\circ} \mathrm{C}$ приводит к увеличению коэффициента поверхностной диффузии на два порядка, что и обеспечивает сглаживание поверхности мишени при нагреве.

Таким образом, в работе проведено исследование нанорельефа, формирующегося при наклонном облучении мишени кластерными ионами, в зависимости от дозы облучения и температуры мишени. Показано, что при комнатной температуре на поверхности развивается рельеф, с увеличением дозы переходящий в упорядоченный волнообразный. Обнаружено, что с увеличением температуры мишени развития рельефа не происходит. Более того, происходит сглаживание исходной шероховатости. Усиление эффекта сглаживания поверхности при повышенной температуре можно использовать для более эффективной планаризации материалов кластерными ионами.

\section{Благодарности}

Авторы выражают благодарность А.А. Татаринцеву и А.С. Трифонову за помощь при микроскопическом исследовании образцов.

\section{Финансирование работы}

Работа выполнена при поддержке Российского фонда фундаментальных исследований (проект № 18-32-20193). 


\section{Конфликт интересов}

Авторы заявляют, что у них нет конфликта интересов.

\section{Список литературы}

[1] Шемухин А.А., Балакшин Ю.В., Черныш В.С., Голубков С.А., Егоров Н.Н., Сидоров А.И. // ФТП. 2014. Т. 48. B. 4. C. 535-538. DOI: $10.1134 / \mathrm{S} 1063782614040265$

[2] Yamada I., Matsuo J., Toyoda N., Kirkpatrick A. // Mater. Sci. Eng. R. 2001. V. 34. P. 231-295.

DOI: $10.1016 / \mathrm{S} 0927-796 \mathrm{X}(01) 00034-1$

[3] Ieshkin A.E., Kireev D.S., Ermakov Yu.A., Trifonov A.S., Presnov D.E., Garshev A.V., Anufriev Yu.V., Prokhorova I.G., Krupenin V.A., Chernysh V.S. // Nucl. Instr. Meth. B. 2018. V. 421. P. 27-31. DOI: 10.1016/j.nimb.2018.02.019

[4] Коробейщиков Н.Г., Николаев И.В., Роенко М.А. // Письма в ЖТФ. 2019. Т. 45. В. 6. С. 30-32. DOI: 10.21883/PJTF.2019.06.47496.17646

[5] Sumie K., Toyoda N., Yamada I. // Nucl. Instr. Meth. B. 2013. V. 307. P. 290-293. DOI: 10.1016/j.nimb.2013.01.087

[6] Lozano O., Chen Q.Y., Tilakaratne B.P., Seo H.W., Wang X.M., Wadekar P.V., Chinta P.V., Tu L.W., Ho N.J., Wijesundera D., Chu W.K. // AIP Adv. 2013. V. 3. P. 062107. DOI: $10.1063 / 1.4811171$

[7] Tilakaratne B.P., Chen Q.Y., Chu W.K. // Materials. 2017. V. 10. P. 1056. DOI: 10.3390/ma10091056

[8] Toyoda N., Tilakaratne B., Saleem I., Chu W-K. // Appl. Phys. Rev. 2019. V. 6. P. 020901. DOI: 10.1063/1.5030500

[9] Киреев Д.С., Данилов А.В., Иешкин А.Е., Черныш В.С. // Вестн. РГРТУ. 2018. № 66. С. 40-48. DOI: $10.21667 / 1995-4565-2018-66-4-2-40-48$

[10] Popok V.N. // Rev. Adv. Mater. Sci. 2014. V. 38. P. 7-16.

[11] Seah M.P. // J. Phys. Chem. C. 2013. V. 117. P. 12622-12632. DOI: $10.1021 / \mathrm{jp} 402684 \mathrm{c}$

[12] Kitani H., Toyoda N., Matsuo J., Yamada I. // Nucl. Instr. Meth. B. 1997. V. 121. P. 489-492.

DOI: $10.1016 / \mathrm{S} 0168-583 \mathrm{X}(96) 00556-3$

[13] Ieshkin A.E., Kireev D.S., Tatarintsev A.A., Chernysh V.S. // Nucl. Instr. Meth. B. 2019. V. 460. P. 165-168. DOI: 10.1016/j.nimb.2019.03.054

[14] Елманов Г.Н., Залужный А.Г., Скрытный В.И., Смирнов Е.А., Яльцев В.Н. Физическое материаловедение. Т. 1. Физика твердого тела. М.: МИФИ. 2007. 636 с. 